\title{
Saúde mental e atenção básica no cuidado aos usuários de álcool e outras drogas
}

Francéli Francki dos Santos ${ }^{(a)}$

Alcindo Antônio Ferla ${ }^{(b)}$

Santos FF, Ferla AA. Mental health and primary care in alcohol and drug users care. Interface (Botucatu). 2017; 21(63):833-44.

The present article approaches the integration between care in mental health and basic attention in Brazilian Unique Health System (SUS). The focus of the discussion is tutors' participation in Caminhos do Cuidado (Care Paths) ProjectTraining in Crack, Alcohol and other drugs given to Community Health Agents and Nursing Technicians and the contribution of Mental Health training for their professional lives. The tutors' participation was analyzed using a secondary data base organized from electronic forms. From a total of 890 questionnaires, we analyzed three open questions using content analysis as a method. The training revealed itself capable of transforming prejudiced images in relation to other drug users and this change has awakened new possibilities for care in primary health care, as well as it developed pedagogical capacities to be used in permanent education in health.

Keywords: Crack, alcohol and other drugs. Primary health care. Caminhos do cuidado. Mental health. Permanent education in health.
Este artigo aborda a integração entre o cuidado em saúde mental e a atenção básica no Sistema Único de Saúde. Discute a participação dos tutores do Projeto Caminhos do Cuidado - Formação em crack, álcool e outras drogas para Agentes Comunitários de Saúde e Auxiliares e Técnicos de Enfermagem, e a contribuição da formação em Saúde Mental para sua vida profissional. A participação dos tutores foi analisada por banco de dados secundários, organizado a partir de formulários eletrônicos. Dos 890 questionários preenchidos, foram analisadas três questões abertas, utilizando-se a Análise de Conteúdo como método. A formação mostrou-se capaz de transformar a imagem de preconceito em relação aos usuários de álcool e outras drogas; essa mudança despertou novas possibilidades para o cuidado na Atenção Básica, além de desenvolver capacidades pedagógicas para a educação permanente em saúde.

Palavras-chave: Crack, álcool e outras drogas. Atenção Atenção primária à saúde. Caminhos do cuidado. Saúde mental. Educação permanente em saúde. (a, b) Programa de PósGraduação em Saúde Coletiva, Universidade Federal do Rio Grande do Sul. Rua Antônio Carlos Guimarães, 155, $1{ }^{\circ}$ Andar. 90050-382 Porto Alegre, RS, Brasil. francelifisio@gmail.com; ferlaalcindo@gmail.com 


\section{Introdução}

Sobre o uso de drogas podemos dizer que esta é uma prática milenar e universal. Está presente em todas as sociedades, variando seus modos de uso, objetivos e alcance. Portanto, o uso de drogas data de tempos remotos e envolve questões religiosas, econômicas, culturais, políticas e sociais ${ }^{1,2}$. Petuco ${ }^{2}$, alicerçado por grandes historiadores do tema do álcool e drogas, nos remete a uma viagem no que ele chama de pequena história do cuidado e das políticas públicas às pessoas que usam álcool e outras drogas. Nesta historieta, percebemos que foi, apenas, no século XIX que os problemas de álcool e drogas, até então de ordem moralista e religiosa, começam a ser vistos pela medicina. Junto a esse movimento iniciava-se o olhar patologizante da questão do uso de álcool e drogas alastrando mundialmente a necessidade de proibição do uso. Esse discurso se fortalece balizado, também, na estratégia de enclausuramento de loucos e pobres em instituições hospitalares ${ }^{3}$.

$\mathrm{Na}$ história do sistema de saúde brasileiro, um longo caminho foi percorrido para que o cuidado às pessoas que usam drogas fosse incorporado às políticas e endereçado aos serviços de saúde, e, em especial, na principal porta de entrada do sistema, que são as unidades de atenção básica. A atenção aos cidadãos em uso dessas substâncias inicia-se no princípio dos anos 1990, com a adoção de uma abordagem voltada para a Redução de Danos (RD), como no conjunto de ações de prevenção à AIDS e, posteriormente, em 2003, com a Política do Ministério da Saúde de Atenção Integral ao Usuário de Álcool e outras Drogas.

A RD é incorporada nessa Política como um dos eixos principais no sentido de garantir a autonomia e o cuidado aos usuários de álcool e outras drogas. A abordagem se opõe à da abstinência, o que não quer dizer que essa não possa ser um objetivo a ser alcançado, desde que seja um desejo do usuário. Enquanto a abstinência está articulada com uma proposta de remissão do sintoma e a cura do doente, a proposta de reduzir danos possui, como direção, a produção de saúde, considerada como produção de regras autônomas de cuidado de $\mathrm{si}^{4}$. Essas duas perspectivas ilustram uma grande diferença na perspectiva do cuidado, na medida em que, na lógica da abstinência, o centro da estratégia está nos serviços especializados e, na 'força de vontade' do sujeito e na perspectiva da RD, na rede de cuidados que opera no território.

A Política de atenção integral ao usuário de álcool e outras drogas marca um novo olhar sobre o usuário, alicerçada na Lei Federal no 10.216, de 2001. Conhecida como lei antimanicomial, propõe a estruturação e fortalecimento de uma rede de assistência centrada na atenção comunitária com ênfase na reabilitação e reinserção social dos usuários. Essa rede de assistência deve ser composta de dispositivos extra-hospitalares articulados com a rede de atenção em saúde mental, com seus diferentes serviços e níveis de atuação, sendo que os dispositivos devem estar ligados à perspectiva da $\mathrm{RD}$ e integrados ao meio cultural e comunitário em que vivem as pessoas em situação de uso. No atual desenho das políticas de atenção à saúde, cabe à atenção básica não apenas constituir-se como porta de entrada, mas mediar o percurso do usuário pelos demais serviços. A preconizada transformação da modelagem tecnoassistencial recoloca o papel da atenção básica na rede de atenção, e, no âmbito da política, amplia sua relevância na gestão do cuidado de todos os sujeitos que ocupam os territórios de referência das equipes. Entretanto, a referência ao cuidado na atenção básica inserida na política não se implantou imediatamente nas práticas de cuidado, sendo necessário um conjunto de iniciativas para essa transformação.

No sentido de aproximar a atenção básica da saúde mental, o Governo Federal incentivou algumas ações junto às equipes de saúde da família. A qualificação profissional para atendimento das demandas de saúde mental foi foco de algumas dessas estratégias. Tomamos como base deste estudo o Projeto Caminhos do Cuidado, que teve, na formação de agentes comunitários de saúde (ACS) e auxiliares e técnicos em enfermagem (ATENF), seu objeto de intervenção. O Projeto Caminhos do Cuidado foi uma iniciativa: do Ministério da Saúde, Fundação Oswaldo Cruz, Grupo Hospitalar Conceição e Universidade Federal do Rio Grande do Sul; visou à formação na temática do crack, álcool e outras drogas para o reconhecimento, atuação e intervenção desses profissionais junto à equipe de Saúde da Família, tendo a Reforma Psiquiátrica e a estratégia de RD como eixos principais 5 . A 'formação' a que nos referimos acima incluía ações de educação permanente em saúde (EPS), com dispositivos para a reflexão sobre a 
relevância do problema no âmbito de cada equipe e território, e conhecimentos e técnicas para uso no cotidiano da ação dos trabalhadores em formação e dos serviços a que pertenciam.

O Caminhos do Cuidado teve, como meta de formação, a totalidade de agentes comunitários de saúde, além de um técnico ou auxiliar em enfermagem das equipes de saúde da família do país, durante os anos de 2013 a 2015. Essa meta foi alcançada e, ao final do período, foram envolvidos 290.197 mil trabalhadores dessas categorias, além de 2.198 tutores formados ${ }^{6}$. A formação dos agentes e técnicos constituiu-se em cinco encontros semanais, intercalados por atividades de dispersão- atividades desenvolvidas em seu território e junto à sua equipe de saúde. O que esteve posto em tensão no processo formativo foi o modo de fazer o cuidado e a articulação entre as proposições das duas políticas, saúde mental e atenção básica, nos serviços de saúde do país inteiro. Além dos ACS e ATENF, o projeto envolveu profissionais que foram selecionados em editais públicos para a função de tutoria.

Esses profissionais receberam uma formação que consistia em 40 horas de atividades, em forma de imersão junto à equipe pedagógica do projeto, e contemplava dois grandes eixos. Primeiro eixo: "Conhecendo o território, as redes de atenção, os conceitos, políticas e as práticas de cuidado em saúde mental". Segundo eixo: "A caixa de ferramentas dos ACS e ATENF na Atenção Básica", tendo como tema transversal a Reforma Psiquiátrica, RD e Integralidade do cuidado. Além da formação presencial, foi disponibilizado, ao tutor, um módulo de educação à distância, possibilitando seu acompanhamento pela equipe pedagógica ao qual deu suporte a sua atividade de tutoria, este módulo não será analisado nesse artigo.

Este artigo é parte da dissertação de mestrado defendida no Programa de Pós-graduação em Saúde Coletiva da Universidade Federal do Rio Grande do Sul, que objetivou discutir acerca da participação dos tutores do Projeto Caminhos do Cuidado e a contribuição da formação em saúde mental, para sua vida profissional. Por meio dessa discussão, analisamos as mudanças possíveis de ocorrerem nas equipes de saúde mental e de atenção básica, a partir do processo de trabalho do tutor, como resultado das novas aprendizagens adquiridas durante a formação de tutores e a prática da tutoria. Esses profissionais foram responsáveis pelas formações dos agentes comunitários de saúde e auxiliares/ técnicos em enfermagem em seu território de atuação, além de serem grandes potencializadores de discussões a respeito dessa temática em seu ambiente de trabalho, pois tinham como prérequisito serem profissionais ligados à docência, atenção básica ou saúde mental. Demonstrou-se que a participação dos tutores se constituiu numa meta não prevista inicialmente, mas com grande potencialidade de alterar modos de cuidar, modos de ensinar e modos de pensar o cuidado com usuários de álcool e outras drogas.

\section{Metodologia}

A participação dos tutores foi analisada por meio da seleção de variáveis de um banco de dados secundários, organizado a partir de formulários preenchidos por eles como dispositivo de avaliação realizado pelo Projeto. Esses formulários foram enviados pela equipe de coordenação nacional do Projeto Caminhos do Cuidado para todos os tutores formados até julho de 2014, totalizando 1.600 tutores. Este instrumento foi disponibilizado entre os dias 14 a 28 de julho de 2014 por meio do formulário online. O instrumento original, que formatou o banco de dados, contou com 35 perguntas, sendo 17 delas qualitativas - podendo ou não serem respondidas pelo tutor. O formulário foi disponibilizado para 1.600 tutores, sendo 890 preenchidos, os quais foram utilizados na pesquisa, caracterizando, assim, uma amostra de conveniência. Por ser um amplo banco de dados, nos detemos em algumas questões que consideramos pertinentes para ajudar a responder os objetivos da pesquisa.

Optou-se por utilizar as seguintes perguntas abertas do questionário dos tutores: "Deseja apontar outros aspectos positivos que podem ser destacados do processo de formação de tutor realizado presencialmente (40 horas)?"; "Qual (is) a (s) contribuição (ões) do Projeto Caminhos do Cuidado para sua formaçãa?" e "Qual (is) a (s) contribuição (ões) do Projeto Caminhos do Cuidado para seu processo de trabalho?" 
Para a organização e análise dos dados qualitativos, optou-se pela Análise de Conteúdo 7,8 . A operacionalização da análise de conteúdo foi feita por meio da categorização temática, com apoio de tecnologias virtuais por meio do Software NVivo 10 for Windows. O uso de sistemas informatizados para essa atividade possibilita o acréscimo ao rigor da organização dos dados coletados e a manipulação de dados complexos ${ }^{7}$.

Nesta pesquisa, não nos detivemos na análise quantitativa gerada por essas categorias empíricas, mas no que essas categorias nos revelaram - por intermédio da fala dos tutores -, sobre a temática do crack, álcool e outras drogas, tendo como disparador a vivência no projeto Caminhos do Cuidado - para o cotidiano de vida e do trabalho desses profissionais. Voltamos a atenção, também, sobre a possibilidade de discutir o cuidado no cotidiano das equipes para o encontro das Equipes de Saúde da Família com a Saúde Mental.

\section{Resultados e discussão}

A categorização temática gerada na análise dos dados resultou em quatro grandes eixos de discussão: Metodologia e ampliação de conhecimentos; Quebra de paradigmas e mudança de olhar em relação ao usuário de álcool e outras drogas; Educação Permanente em Saúde; Ampliação da clínica.

\section{Processo formativo}

O processo formativo era uma etapa da seleção de tutores para o Projeto Caminhos do Cuidado e acontecia em regime de imersão de cinco dias consecutivos. Segundo os tutores, esse foi um importante período para vivenciar o material didático, as dinâmicas e as discussões que futuramente seriam realizadas com os ACS e ATENF.

A metodologia surgiu na análise com um expressivo número de respostas no que se refere aos aspectos positivos da formação e, também, aparece como sendo de grande contribuição para a formação profissional dos tutores, como podemos perceber de falas a seguir, levando a acreditar que metodologias ativas, como a utilizada no Caminhos do Cuidado, têm uma forte aceitação pelo seu caráter crítico-reflexivo, dinâmico e horizontal.

\footnotetext{
"A metodologia ativa utilizada no processo de aprendizagem ficou como experiência para outras áreas do meu dia a dia no trabalho. A metodologia foi incrível, manteve o interesse da turma e possibilitou o entendimento sobre o saber construído através de muitos olhares."

"[....] Enfim é a primeira vez que tenho oportunidade de trabalhar com algo que é estimulante desde o primeiro até o último encontro."

"[...] O Caminhos do Cuidado é especialmente diferenciado no processo do "SABER", onde o domínio do conhecimento não está em indivíduos, mas na construção coletiva, nos valores multipessoas. Contanto, isso me possibilitou ampliar meu olhar da formação para um saber ampliado e compartilhado."
}

A formação do Caminhos do Cuidado reiterou a necessidade de se repensar novas práticas educativas para os profissionais de saúde, uma vez que a educação tradicional já não corresponde mais às expectativas e necessidades de profissionais submetidos a processos formativos de qualquer natureza.

As metodologias ativas utilizam a problematização como estratégia de ensino-aprendizado, com o objetivo de se aproximar e motivar o estudante, pois, diante do problema, ele reflete, relaciona a sua história e passa a ressignificar as suas descobertas ${ }^{9}$. No caso do Projeto Caminhos do Cuidado, além de se utilizar a metodologia ativa, foram tomados como base os conceitos pedagógicos propostos por Paulo Freire. 
Paulo Freire ${ }^{10}$ propõe uma educação que enfatize a práxis, na qual o sujeito busque soluções para a realidade em que vive e, após a reflexão, possa transformá-la. Ao contrário da educação tradicional, bancária e verticalizada, a educação libertadora freireana se propõe a ser crítica, criativa, responsável e comprometida. Segundo Freire ${ }^{10}$, quem ensina, aprende ao ensinar, e quem aprende, ensina ao aprender. Ainda no bloco anterior, foi possível perceber que os tutores estiveram diretamente ligados ao efeito de ensinar-aprender-ensinar, pois, um grande número deles relata que foi de extrema importância a troca de aprendizado e experiências com os ACS e ATenf. Esse aprendizado mútuo foi possibilitado por meio da ação problematizadora realizada pelos tutores e pelas experiências da prática vivida no território por esses profissionais; a discussão da prática permite o retorno ao campo de trabalho com outras ferramentas para intervenção.

Na EPS, o processo de trabalho é tomado como objeto da reflexão participativa e ativa pelos trabalhadores. É a partir da realidade, de suas práticas, das concepções que portam e de suas relações de trabalho que se constroem os processos educativos ${ }^{11}$. Para Feuerwerker ${ }^{11}$, a EPS parte do pressuposto de que somente desde a realidade local e da singularidade dos atores é possível construir processos que façam sentido e que sejam, efetivamente, apropriados pelos trabalhadores em seu cotidiano.

Dentre os aprendizados adquiridos pelos tutores, podemos destacar a RD como o tema que apareceu com mais frequência, tanto que mereceu uma categorização específica, já que é um dos eixos centrais da formação, junto com a reforma psiquiátrica - ao mesmo tempo em que alguns tutores colocaram a necessidade de ampliação da discussão sobre RD na carga horária destinada à formação de tutores.

Temos a RD como uma estratégia de cuidado ao usuário de álcool e outras drogas, que se coloca contra-hegemônica no tratamento dessa população, pois desinstitucionaliza e desmedicaliza o cuidado, além de tornar o usuário o protagonista dessa relação durante o tratamento. Com base nesse argumento, podemos arriscar em dizer que, mesmo aqueles tutores que não relataram explicitamente a RD como conhecimento ampliado, foram tocados pela temática quando disseram que aprenderam sobre a construção de um novo olhar e novas abordagens em saúde para um cuidado integral. A temática da RD segue em mais um bloco de depoimentos:

(Falando da contribuição do Projeto para sua formação) "Toda, não possuía formação alguma para trabalhar com RD, e atualmente já estou formando grupos dentro das UBS do município em que trabalho para atuarmos diretamente com os familiares dos usuários, pois assim poderemos conseguir uma adesão maior."

"O projeto ampliou minhas percepções a respeito do cuidado em saúde mental, sobretudo na questão do álcool, crack e outras drogas, assim como RD. Após a formação, me interessei pelo tema e tenho aprofundado cada vez mais os conteúdos."

\section{Quebra de paradigma e mudança de olhar em relação ao usuário de álcool e drogas}

Esta categoria empírica apresentou registros que apontaram para a mudança de olhar e desconstrução de preconceitos e paradigmas em relação aos usuários de álcool e outras drogas, gerada a partir do processo formativo presencial de $40 \mathrm{hs}$, realizado pelos tutores do Projeto Caminhos do Cuidado.

Um número considerável de tutores respondeu que a contribuição do Caminhos do Cuidado para a sua vida profissional foi transformar seu olhar ("enxergar além das aparências") em relação aos usuários de álcool e outras drogas, deslocando a imagem de preconceito e receio em relação a esses indivíduos para a imagem de um indivíduo com desejos, singularidades e dotado de histórias de vida, quebrando paradigmas e construindo novas formas de ver o usuário. A mudança nesse 'olhar' também fez com que o profissional visualizasse possibilidades para mudanças de práticas, podendo criar alternativas para o cuidado e para o desenvolvimento da cidadania dessas pessoas. 
"Apesar de ser psicóloga, ainda tinha algumas barreiras com o dependente químico, depois da formação com certeza venho melhorando isso em mim a cada dia."

Evidenciamos que a participação no Projeto fez com que esse profissional mudasse seu modo de ser e/ou agir a partir dos novos conhecimentos adquiridos. Isso também pode ser percebido nas falas que seguem, em que os mesmos relatam que há um deslocamento da imagem dos usuários de álcool e outras drogas, e que essa mudança possibilitou a abertura para novas formas de cuidado em saúde. Para Pinheiro e Ceccim ${ }^{12}$, uma prática cuidadora envolve o assistir e/ou tratar segundo os parâmetros do acolher e respeitar, isto é, dar lugar às singularidades, compreender as fragilidades e estar presente de maneira correspondente.

"[...] a maior contribuição é a do relacionamento interpessoal, de criar laços, acreditar nas pessoas, de ver além da aparência, de saber que por trás de uma aparência existe um ser que é um oceano de subjetividade que é livre para escolher. Acima de tudo não julgar o outro por suas escolhas, mas criar possibilidades e alternativas."

"[.... Mudou o meu olhar em relação aos pacientes com transtornos mentais e em uso de substâncias psicoativas, porque antes agia em parte de forma preconceituosa, mas com o curso passei a ter um olhar diferenciado, a ver os pacientes como um todo, ou seja, com suas singularidades, histórias, sentimentos e não em parte, o que quero dizer é que passei a ver um ser humano e não a substância."

Os tutores reconheceram o ambiente do Caminhos do Cuidado como privilegiado para mudanças formativas, o que não é percebido em espaços formais, como a universidade, que, em muitos casos, se abstém das discussões sobre o cuidado ampliado aos usuários de álcool e outras drogas, pois foge do escopo formal biomédico costumeiramente adotado pelas instituições de ensino em saúde.

"O Projeto Caminhos do Cuidado foi o que mais me confirmou que é sim possível mudar o olhar que temos pré-estabelecido que vem da educação formal/conservadora. Hoje me sinto renovada com a possibilidade de mudanças/avanços em minha formação."

"A perspectiva de se trabalhar com um novo olhar para o usuário de álcool e outras drogas que de maneira nenhuma acontece nos espaços formativos normais!"

De acordo com Ceccim e Ferla ${ }^{13}$, a formação dos profissionais de saúde tem se mostrado de grande resistência aos avanços da cidadania em saúde, conquistada pela Reforma Sanitária Brasileira, sendo ainda desafiadora a formação dos profissionais de saúde para o trabalho no SUS. Sendo a formação uma tarefa socialmente necessária, ela deve guardar, para a sociedade, compromissos ético-políticos, e não pode estar atrelada aos valores tradicionais, mas ao movimento de transformações na sociedade ${ }^{14}$.

\section{Educação permanente em saúde}

Após a análise dos questionários, ficou evidente a necessidade de os profissionais de saúde saírem dos seus ambientes de trabalho para interagirem com outras realidades do seu território ou compartilharem experiências do mesmo. Tal constatação foi possível pelo expressivo número de tutores que consideraram, como de grande relevância, a possibilidade que o Caminhos do Cuidado trouxe para a interação entre trabalhadores de saúde de diferentes formações profissionais e de diferentes estados e municípios; e a potencialidade que as trocas de experiências realizadas por eles acrescentou aos seus cotidianos de trabalho. Essa constatação pode ser evidenciada nas falas que seguem: 
“A integração de profissionais de vários municípios, com realidades distintas, além da multidisciplinaridade, proporcionou os diversos olhares e práticas, que enriqueceram o processo de construção de novos saberes."

"Troca de experiência com os profissionais das equipes dos diversos municípios, as dificuldades socializadas, as experiências exitosas desses profissionais comprometidos no fazer profissional."

"Muitas, em especial a interação com os ACS e ATENF, que trazem situações reais e práticas muito valiosas. De certa forma cada situação nos faz pensar e agir de maneiras diferentes e com certeza hoje a visão é outra."

Nesses relatos, podemos perceber quanto foi valorizada, pelo tutor, a troca de experiências proporcionada pelo Caminhos do Cuidado tanto no momento da formação de tutores, como nos momentos em que estiveram próximos às equipes de Saúde da Família, nas atividades de formação dos ACS e ATENF. A possibilidade de socialização de dificuldades, ao mesmo tempo que eram absorvidas experiências exitosas para o cotidiano dos trabalhadores de saúde, fez com que esses momentos se tornassem grandes espaços de EPS. Para Mehry"15, a "Educação Permanente é a prática sistemática de aprendizagem nossa (trabalhadores de saúde) com nosso próprio fazer do cotidiano do trabalho e com a capacidade criativa de inventar esse cotidiano". Para ele, a EPS é capaz de "produzir mobilidades no território mesmo que esse território nos convida a imobilidade".

O envolvimento dos tutores com a temática foi tão grande que muitos relataram que o processo formativo instigou a busca de mais conhecimento na área da saúde mental para trabalhar com essa população, e até outras formas de aperfeiçoamento profissional, produzindo novas 'mobilidades' na vida pessoal e profissional desses trabalhadores. A EPS requer que seus atores se sintam convocados à criação, à abertura e ao coletivo. O investimento pedagógico é para poder quebrar o que está dado, ampliar as noções de autonomia do outro e construir espaços criativos e sensíveis na produção da saúde ${ }^{13}$.

\footnotetext{
“Com as aulas aumentou meu interesse pelos conteúdos teóricos relacionados ao cuidado e problemática sobre álcool e drogas. Assim, as aulas ficam mais interessantes e eu me torno uma profissional mais interessante também[...]"
}

"Muito aprendizado teórico e prático. Academicamente, um estímulo para a continuidade nos estudos na área de saúde mental. Pretendo cursar mestrado nesta área."

\footnotetext{
"Muito aprendizado, pois na sala de aula acontecem muitas trocas e a cada aula dada aprendo mais. Me fez também pesquisar sobre o tema para me apropriar mais sobre o assunto."
}

\section{Ampliação da clínica}

Como sabemos, a Atenção Básica deve buscar o atendimento integral e de qualidade aos usuários, além do fortalecimento da autonomia das pessoas sob seu cuidado, estabelecendo a articulação com a rede de serviços. De acordo com Neves e Paulon ${ }^{16}$, para que o princípio da integralidade deixe de ser uma indicação dogmática do SUS, a Atenção Básica deve ser compreendida e funcionar como espaço de acolhida para questões de saúde mental. Isso tudo estaria relacionado com a possibilidade de o usuário ser acompanhado em seu contexto social, "tratado nas tramas que organizam suas vidas" 17 e sob a perspectiva de vínculos, escuta e acolhimento da equipe multiprofissional em Saúde da Família.

Durante a leitura do banco de dados, podemos perceber que um número significativo de tutores considerou o projeto importante para ampliar seus modos de fazer saúde na atenção básica ou em outros locais de trabalho. Esses profissionais relataram que o projeto ampliou sua compreensão acerca das possibilidades de cuidado na atenção básica para com os usuários de crack, álcool e outras drogas Como podemos perceber a seguir, há registro de um deslocamento nas imagens dos tutores sobre a interface entre pessoa necessitando de cuidados, uso problemático de drogas e atenção básica, que 
parece estabelecer possibilidades de outras relações entre os sujeitos - na cena do cuidado - mais próximas de um cuidado integral. Aqui, as imagens das relações entre atenção básica, pessoas e uso de drogas procura dar visibilidade a aspectos que tornam possível a oferta de uma combinação singular de tecnologias duras, leve-duras e leves com base na complexidade de necessidades do usuário dos serviços, conforme os conceitos formulados por Merhy ${ }^{18}$.

\footnotetext{
"Mudança na minha percepção em relação ao usuário de drogas, sobretudo, em relação aos cuidados que estes devem ter na Atenção Básica."
“Trabalho há anos em saúde mental e tinha um certo receio, achava não ter perfil para trabalhar com usuário de drogas. Após a formação fiquei surpresa e percebi que na verdade eram alguns preconceitos que ainda existiam e que começaram a ser diluídos na formação. Hoje o olhar é muito diferente e contribui imensamente para um trabalho de qualidade e cuidado adequado."

\begin{abstract}
“O projeto viabiliza a elaboração de propostas concretas de trabalho com a temática (possibilidades de cuidados), potencializando a Atenção Básica como espaço privilegiado de assistência à saúde mental, usuários de crack, álcool e outras drogas."
\end{abstract}

Os registros destacados apontam algumas questões de relevância para a mobilização de práticas cuidadoras no âmbito dos serviços. Percebe-se uma conexão entre a Atenção Básica e o cuidado com pessoas usuárias de drogas, conectando potencialidades entre essas duas áreas de atenção, na mesma direção à qual apontam as políticas e a orientação do Caminhos do Cuidado. Percebe-se, também, deslocamentos de imagens prévias, demonstrando a tomada de consciência em relação ao preconceito, com a questão do uso de drogas. "Receio", "preconceito" e um "olhar" marcado pela produção de uma "identidade fixa" ao usuário de drogas, ademais, o torna um "não possível" ao cuidado; e, ainda mais, na Atenção Básica, é reificar uma imagem âncora da vigência atual. Por fim, no último registro deste bloco, é afirmada a Atenção Básica como lugar "privilegiado" de cuidado às pessoas em situação de uso de drogas e da formação como oferta de possibilidades concretas para organizar esse cuidado.

Que cuidado é esse de que estamos falando? Quais são os cuidados possíveis em Saúde Mental na Atenção Básica? Um cuidado que dá visibilidade, voz, vez? Do cuidado como direito do cidadão, não só constitucional, mas ético, inerente ao campo de conhecimento dos profissionais de saúde. Um cuidado que busca a autonomia, a capacidade do sujeito em gerir sua vida, segundo suas escolhas e singularidades. Esse é o registro nas diferentes políticas, mas, também, nas construções de pensamento que embasam as políticas e as teorias de cuidado. Parece ser, da mesma forma, um deslocamento apontado pelos tutores, conforme podemos perceber nas falas anteriores.

Ações cuidadoras aos usuários de álcool e outras drogas requerem estratégias focadas no indivíduo e nas coletividades utilizando-se a rede de atenção à saúde-formal ou não ${ }^{17}$. O rótulo de 'usuário de álcool e drogas' é usado comumente como motivo para diminuir as chances de esse indivíduo receber cuidados, desconsiderando, inclusive, outras necessidades de saúde que acontecem ao longo da vida, como uma gestação, hipertensão, diabetes... Esses pacientes caem no que se pode chamar de buraco da rede: eles não são atendidos na Atenção Básica, porque estão em sofrimento psíquico, e não são atendidos na saúde mental porque estão com alguma doença que não se pode tratar ali'19. Sabemos que esse tipo de ação é casual na Atenção Básica por diversas razões, uma das justificativas é a baixa capacidade dos profissionais para lidarem com essas questões ${ }^{16}$.

Merhy ${ }^{18}$ nos faz refletir sobre a dimensão micropolítica do trabalho capaz de produzir atos cuidadores, independentemente da função técnica que esse trabalhador desempenha na equipe de saúde, em que as relações entre trabalhadores e usuários dos serviços toma a dupla dimensão de constituir uma natureza de tecnologias para o cuidado e, ao mesmo tempo, um dispositivo de regulação para padrões ampliados de cuidado.

Como constituir uma relação trabalhador-usuário mais potente de cuidado se a imagem do outro está restrita a uma identidade fixa, facilmente capturada por uma interpretação moral que a desvincula 
da saúde e a conecta na configuração moral e na personalidade dos sujeitos? Essa questão nos faz pensar sobre a necessidade de utilização de outros recursos da caixa de ferramentas - conjunto de saberes que o profissional dispõe para a produção de atos de saúde - para a organização do trabalho nas equipes de saúde a fim de produzirem atos de saúde capazes de gerar ações cuidadoras resultantes não somente em cura, mas em promoção e proteção da saúde individual e coletiva.

Trazemos essa reflexão para pensarmos as possibilidades de cuidado aos usuários de álcool e outras drogas que vêm sendo utilizadas pelos profissionais, e de quais possibilidades podemos lançar mão. Sobretudo, para organizar uma análise dos efeitos da formação do Caminhos do Cuidado no cotidiano na saúde, que, afinal, é a dimensão que pede visibilidade quando se pensa em EPS. Esta permite tomar o cotidiano como lugar aberto à revisão permanente e gerar o desconforto com os lugares 'como estão/como são'; deixar o conforto com as cenas 'como estavam/como eram' e abrir os serviços como lugares de produção de subjetividade; tomar as relações como produção, como lugar de problematização, como abertura para a produção ${ }^{20}$.

O trabalho em saúde vem adotando procedimentos altamente técnicos e que dispõem cada dia mais de um saber especializado, deixando em segundo plano as tecnologias leves ${ }^{20}$. Para Feuerwerker ${ }^{11}$, as lógicas de poderes que operam em nossa sociedade tendem a favorecer os núcleos vinculados às tecnologias leve-duras e duras. Superar essa conformação exige novos arranjos, novas combinações tecnológicas em que o peso das tecnologias leves seja maior e que as necessidades dos usuários ocupem um lugar central.

Como podemos perceber, nos registros que seguem, os tutores percebem que a Atenção Básica é um local privilegiado para o cuidado dos indivíduos, e, por meio do Caminhos do Cuidado, conseguem, também, deslocar a imagem de cuidado em saúde mental vinculado apenas aos centros especializados. A possibilidade de ampliação da clínica passou pela incorporação de novos arranjos de cuidado com atendimento chamado de mais humanizado e a utilização da RD como mais uma ferramenta de cuidado.

\footnotetext{
"Para minha formação enquanto psicólogo foi muito valiosa. Por possibilitar transmitir a diferença; e contribuir assim, para um tratamento mais humanizado à saúde mental."

“Trabalho em uma ESF e sou docente para o curso de graduação em enfermagem, e o conhecimento adquirido no curso tem melhorado muito o meu atendimento a este segmento da população, bem como tenho estimulado meus alunos a repensarem o atendimento destes pacientes[...]."
}

"Qualificou minha intervenção na Atenção Básica, tanto no que se refere à Saúde Mental como em relação à qualidade do cuidado na Atenção Básica."

\section{Conclusões}

$\mathrm{Na}$ análise dos registros feitos pelos tutores do projeto Caminhos do Cuidado, percebeu-se que houve um deslocamento da imagem dos usuários de álcool e outras drogas, que passaram a ser vistos como indivíduos com desejos, singularidades e histórias de vida, abrindo-lhes a possibilidade de serem cuidados por estes profissionais nos serviços de saúde com algo a menos de receio e preconceito. Aliado à mudança no modo de ver o usuário, evidenciou-se que os tutores perceberam novas possiblidades de cuidado aos usuários de álcool e outras drogas, e compreenderam a Atenção Básica como espaço privilegiado para esse cuidado. Podemos dizer que o Caminhos do Cuidado potencializou a reflexão a respeito das práticas de cuidado para usuários de álcool e outras drogas, configurando, também, um importante passo para a ampliação da oferta de cuidado a esses indivíduos na Atenção Básica. Evidentemente que essa iniciativa não teve a capacidade de mudar a cultura dos serviços em relação aos usuários, mas as evidências nos registros dos tutores apontam para uma ampliação na capacidade de ver o problema como uma questão de cuidado. 
Apesar de os tutores do Caminhos do Cuidado também serem profissionais da Atenção Básica, é possível supor que esta formação, pontual, não será suficiente para mudar completamente conceitos e práticas adotadas ao longo de muito tempo. Por essa razão, será necessária a manutenção de processos de EPS com a mesma temática para outros profissionais. Inclusive, pelo fato de que, nas práticas do cotidiano, conceitos e imagens se transformam, mas, também, se reapresentam, pois esse não é um processo linear e isento de tensões e contradições. É de extrema importância os profissionais da Atenção Básica estarem afinados com a proposta do Caminhos do Cuidado para que possam acolher as demandas vindas do território, geradas a partir do processo formativo dos ACS e ATENF. Sobretudo, é fundamental que as questões que emergem sempre e por todos os lados no cotidiano do trabalho sejam objeto de autoanálise dos trabalhadores e das equipes, tornando-as dispositivos de adensamento das práticas e desenvolvimento do trabalho, conforme nos sinalizam Ceccim \& Ferla ${ }^{13}$.

Importante considerar que esse estudo analisou os registros realizados durante a formação, na fase de implementação do projeto, o que mostra mais a perspectiva que os tutores constituíram para atuar na função específica que tiveram no projeto. A avaliação do efeito da formação, nos tutores e nos agentes e técnicos, por certo, requer estudos específicos ao longo do tempo. Mas é importante registrar que, mesmo com os limites apontados, é possível identificar uma mudança de perspectiva no universo dos tutores que respondeu às questões formuladas na avaliação, demonstrando um efeito das ações de educação permanente na constituição de novas perspectivas para a ação educativa dos sujeitos.

O Projeto Caminhos do Cuidado colocou o cotidiano do trabalho e a formação dos tutores em análise, potencializada por meio dos espaços de troca vivenciados por eles na formação de tutores, nos encontros com ACS e ATENF, bem como nos municípios por onde passaram. Esse espaço de EPS fez despertar, nos profissionais envolvidos, novas possibilidades de cuidado aos usuários de crack, álcool e outras drogas, estimuladas, também, por uma metodologia de formação crítico-reflexiva. A formação e o convívio com as turmas de ACS e ATENF proporcionaram, além disso, o acúmulo de novos saberes, ampliando, dessa forma, sua "caixa de ferramentas", a ser utilizada no cotidiano do trabalho. Dentre as aprendizagens adquiridas, a RD foi a mais citada pelos tutores, a qual ainda aparece como uma temática desconhecida a muitos profissionais. O trabalho comprometido com o cuidado produz invenções, e é fundamental que essas invenções tenham condições de atravessar as práticas e serem compartilhadas pelos diferentes atores.

\section{Colaboradores}

Os autores Francéli Francki dos Santos e Alcindo Antônio Ferla tiveram participação ativa na elaboração, revisão e aprovação final do manuscrito.

\section{Referências}

1. Fonseca EM, Bastos FI. Os tratados internacionais antidrogas e o Brasil: políticas, desafios e perspectivas. In: Alarcon S, Jorge MAS, organizadores. Álcool e outras drogas: diálogos sobre um mal-estar contemporâneo. Rio de Janeiro: Fiocruz; 2012. p. 15-42.

2. Petuco DRS. Era uma vez: uma pequena história do cuidado e das políticas públicas dirigidas a pessoas que usam álcool e outras drogas. In: Teixeira $M$, Fonseca $Z$, organizadores. Saberes e práticas na atenção primária à saúde: cuidado à população em situação de rua e usuários de álcool, crack e outras drogas. São Paulo: Hucitec; 2015. p. 179-200.

3. Foucault M. Microfísica do poder. Rio de Janeiro: Edições Graal; 2010.

4. Passos EH, Souza TP. Redução de danos e saúde pública: construções alternativas à política global de "guerra às drogas". Psicol. Soc. 2011; 23(1):154-62. http://dx.doi. org/10.1590/S0102-71822011000100017 
5. Ministério da Saúde (BR). Secretaria de Gestão do Trabalho e Educação na Saúde. Projeto Caminhos do Cuidado: Formação de Agentes Comunitários de Saúde, Auxiliares e Técnicos de Enfermagem da Saúde da Família - em saúde mental ênfase em crack, álcool e outras drogas. Brasília, DF: SGTES; 2013.

6. Ministério da Saúde (BR). Secretaria de Gestão do Trabalho e Educação na Saúde. Caminhos do Cuidado: relatório 2015. Rio de Janeiro: Fiocruz/Icict; 2016.

7. Minayo MCS. O desafio do conhecimento: pesquisa qualitativa em saúde. São Paulo: Hucitec; 2008.

8. Bardin L. Análise de conteúdo. Lisboa: Edições 70; 2010.

9. Mitre SM, Siqueira-Batista R, Girardi-de-Mendonça JM, Morais-Pinto NM, Meirelles $C A B$, Pinto-Porto $C$, et al. Metodologias ativas de ensino-aprendizagem na formação profissional em saúde: debates atuais. Cienc Saude Colet. 2008; 13(Supl 2):2133-44. http://dx.doi.org/10.1590/S1413-81232008000900018

10. Freire P. Pedagogia do oprimido. São Paulo: Paz e Terra; 1996.

11. Feuerwerker LC. Micropolítica e saúde: produção do cuidado, gestão e formação. Porto Alegre: Rede Unida; 2014.

12. Pinheiro R, Ceccim RB. Experienciação, formação, cuidado e conhecimento em saúde: articulando concepções, percepções e sensações para efetivar o ensino da integralidade. In: Pinheiro R, Ceccim RB, Mattos RA, organizadores. Ensinar saúde: a integralidade e o SUS nos cursos de graduação na área da saúde. Rio de Janeiro: Abrasco; 2011.

13. Ceccim RB, Ferla AA. Educação e saúde: ensino e cidadania como travessia de fronteiras. Trab Educ Saude. 2009; 6(3):443-56.

14. Ceccim RB, Feuerwerker L. O quadrilátero da formação para a área da saúde: ensino, gestão, atenção e controle social. Physis. 2004; 14(1):41-65. http://dx.doi.org/10.1590/ S0103-73312004000100004

15. Merhy EE, EPS em movimento. [Internet]. 2014 [Citado 16 Ago 2015]. Disponível em: <https://www.youtube.com/watch?v=0-nApG0Wgks 2014>.

16. Neves R, Paulon S. Apresentação. In: Paulon S, Neves R, organizadores. Saúde mental na atenção básica: a territorialização do cuidado. Porto Alegre: Sulina; 2013.

17. Lancetti A, Amarante P. Saúde mental e saúde coletiva. In: Campos GWS, Minayo MCS, Akerman M, Júnior MD, Carvalho MY, organizadores. Tratado de saúde coletiva. São Paulo: Hucitec; 2012.

18. Merhy EE. Saúde a cartografia do trabalho vivo em ato. São Paulo: Hucitec; 2007.

19. Macerata I. Vulnerabilidades do usuário e vulnerabilidades da atenção: apontamentos iniciais para uma clínica de território na atenção básica. In: Ramminger T, Silva $M_{\text {, }}$ organizadores. Mais substâncias para o trabalho em saúde com usuários de drogas. Porto Alegre: Rede Unida; 2014.

20. Ceccim RB. Educação permanente em saúde: desafio ambicioso e necessário. Interface (Botucatu). 2005; 9(16):161-77. 
Santos FF, Ferla AA. Salud mental y atención primaria en atención a los usuarios de alcohol y otras drogas. Interface (Botucatu). 2017; 21(63):833-44.

Este artículo aborda la integración entre el cuidado en salud mental y la atención básica en el Sistema Único de Salud. Discute la participación de los tutores del Proyecto Caminos del Cuidado - Formación en crack, alcohol y otras drogas para Agentes Comunitarios de Salud y Auxiliares Técnicos de Enfermería y la contribución de la formación en Salud Mental para su vida profesional. La participación de los tutores fue analizada por banco de datos secundarios, organizado a partir de formularios electrónicos. De los 890 cuestionarios llenados, se analizaron tres preguntas abiertas, utilizándose como método el Análisis de Contenido. La formación se mostró capaz de transformar la imagen de prejuicio en relación a los usuarios de alcohol y de otras drogas; ese cambio despertó nuevas posibilidades para el cuidado en la Atención Básica, además de desarrollar capacidades pedagógicas para la educación permanente en salud.

Palabras clave: Crack, alcohol y otras drogas. Atención primaria de la salud. Caminos del cuidado. Salud mental. Educación permanente en salud. 